\title{
Population Heterogeneity and Genomic Admixture: Relevance for Global Pharmacogenetics
}

\section{Jorge Duconge*}

School of Pharmacy, University of Puerto Rico Medical Sciences Campus, San Juan, PR, USA

\section{Editorial}

The use of clinical algorithms derived by linear regression analyses is a standard method in medicine, but the empirical and descriptive nature of this kind of model also results in a number of limitations and drawbacks, exemplified by the COAG and EU-PACT trials (ClinicalTrial.gov identifier NCT00839657 and NCT01119300, respectively). Regression-based models are data-driven and, therefore, population-dependent. Accordingly, they are expected to be only valid in the same patient population on which they were originally derived (i.e., mostly in Caucasians) [1-3].

Indeed, such data-driven methods are at increasing risk of overfitting the data, giving rise to a so-called "prediction" model that is not generalizable to other datasets or populations [4]. In addition, statistical analysis used to this purpose can be biased by linkage disequilibrium (LD) structure, admixture patterns and differences in minor allele frequencies (MAF) between and within populations. Population specificity is the most likely explanation to the poor predictability found in African-Americans in the COAG trial. It is becoming increasingly clear that many of the currently available pharmacogenetic-guided algorithms for warfarin dosing predictions do not work well in people with substantial African heritage. This poor predictability seems to be related to the omission of some important variants in the models (e.g., CYP2C $9{ }^{\star} 5,{ }^{\star} 6,{ }^{\star} 8$ and ${ }^{\star} 11$ ), which have proven to be clinically relevant in Africans [5-8]. Consequently, any extrapolation to a different, poorly characterized population with remarkable heterogeneity (e.g., AfricanAmericans, Amerindians or admixed Hispanics) will be flawed. It is important to mention that none of these two clinical trials recruited a significant portion of Hispanics.

I agree with authors of the COAG trial [9] as to their results suggested no improvements on anticoagulation control in patients starting warfarin therapy by using a genotype-guided versus a clinicallydriven dosing algorithm. Despite the fact that this trial showed nonsuperiority (but also non-inferiority) of genotyping over standard clinical procedures (i.e., to stabilize patients on warfarin during the first 4 -weeks of therapy), a significant interaction between race and dosing strategy was found. Noteworthy, the primary outcome slightly improved among non-blacks in the genotype-guided group versus those in the clinical group ( $49 \%$ vs. $46 \%$; adjusted mean difference $2.8 \%, \mathrm{p}=0.15$ ) [9]. Furthermore, authors of the EU-PACT trail found a moderate but significantly better control of anticoagulation in the genotypeguided dosing group (adjusted difference of 7\%; $p<0.001$ ) [10]. In this trial, $\sim 99 \%$ of patients enrolled are Whites from Europe. There were also significantly fewer incidences of excessive anticoagulation, as measured by INR $\geq 4$ levels, in the pharmacogenetically controlled group. Based on their results, both the COAG and the EU-PACT trial $[9,10]$ provided further evidence in favor of a need to develop and test more comprehensive, multi-ethnic pharmacogenetic-based dosing algorithms in order to draw valid conclusions and make adequate recommendations about the potential clinical utility of genotyping patients on warfarin.
A measure of ancestral admixture proportions needs to be included as a critical predictor in order to expand the pharmacogenetic-guided prediction models to mixed populations. Admixture is cardinal for a proper adoption of the clinical pharmacogenetic paradigm in medical practice as multi-gene algorithms are developed to predict variability of certain phenotypes or quantitative traits (e.g., differences in dose requirements). Our group has extensively assessed the role of admixture in the pharmacogenetics of Caribbean Hispanics [11-13] Human genetic diversity has long been considered a major topic in biomedical sciences. Admixture is a surrogate for ethno-geographic genetic diversity not measured by common polymorphisms on target pharmacogenes and, therefore, it can capture a significant proportion of the missing "genetic heritability" in genotype-guided drug prescribing algorithms. Moreover, failure to control for the effect of population stratification by admixture may give rise to a confounder in pharmacogenetic studies. A previous work on the effect of $\mathrm{NQO1}^{\star} 2$ and CYP4F2 V133M genotypes on warfarin dose requirements in Hispanic and African Americans successfully incorporated ancestry measurements as a predictor of dose variability [14]. Other studies have also considered measures of ancestry in the pharmacogenetics of warfarin by using PCA metrics [4]. The utility of genetic ancestry and admixture measures has been postulated early, emphasizing the need to be cautious when extrapolating genetic results from a homogeneous population to admixed ones [15-17].

On the other hand, differences in LD by ancestry can alter associations of well-known genetic markers with warfarin dose requirements across populations. Differential association suggests that certain genetic variants on relevant loci (i.e., some highly prevalent in Caucasians) are not causal mutations but rather in LD with functional variants (e.g., rs12777823 in African Americans and VKORC1-1639G >A in Asians) that occur preferentially in a particular ethnic group. Given the unique pattern of mixture, $\mathrm{LD} /$ haplotype architecture and recombination events occurred in admixed population like Caribbean Hispanics, it is expected that some new putative markers or association signals arise from these events.

There are, of course, other elements to consider in the interpretation of negative results from the COAG trial. First, the clinical value of a pharmacogenetic test decreases when our current predictive ability is high (e.g., INR). Secondly, regression analyses usually fail to explain

*Corresponding author: Jorge Duconge, School of Pharmacy, University of Puerto Rico Medical Sciences Campus, Pharmacy Bldg., $3^{\text {rd }}$ floor, Room 325-14; PO Box 365067, San Juan, PR 00936-5067, USA, Tel: (787) 7582525 ext. 5312; Fax: (787) 767 2796; E-mail: jorge.duconge@upr.edu

Received December 24, 2014; Accepted December 26, 2014; Published December 30, 2014

Citation: Duconge J (2014) Population Heterogeneity and Genomic Admixture: Relevance for Global Pharmacogenetics. J Pharmacogenomics Pharmacoproteomics 5: e141. doi:10.4172/2153-0645.1000e141

Copyright: () 2014 Duconge J. This is an open-access article distributed under the terms of the Creative Commons Attribution License, which permits unrestricted use, distribution, and reproduction in any medium, provided the original author and source are credited. 
Citation: Duconge J (2014) Population Heterogeneity and Genomic Admixture: Relevance for Global Pharmacogenetics. J Pharmacogenomics Pharmacoproteomics 5: e141. doi:10.4172/2153-0645.1000e141

causality in the observed association between dose variability in the patient population and any of the clinical or genetic variables used as regressors. A further limitation is that they are usually derived originally from patients stable on warfarin (i.e., maintenance doses), to then be used for a priori predictions of initial doses. Additionally, regression analysis only address variability in extent, but not rate of response or the well-known time-delay between the pharmacokinetic and pharmacodynamic effects of warfarin. Accordingly, they cannot explain temporal aspects of warfarin response (e.g., anticoagulation control over time as measured by the mean percentage of time in the therapeutic INR range). Finally, common genetic variants included in the pharmacogenetic model of this trial only accounted for sensitivity but not for resistant phenotypes.

A more optimal philosophy for global pharmacogenetics is to guide medical predictions by using DNA-guided algorithms that also accounts for the effect of admixture. Experimental designs with measures of admixture included will propel the full potential of implementing genetically-guided drug therapies to advance global health. The conclusion of the COAG study is valid for the average patient within the context of the study design and its limitations, but not necessarily remains true for a global, admixture-adjusted, multiethnic algorithm. A clinical benefit will only be tangible for those individuals thoroughly represented in the derivation cohort of the prediction model. Recruitment of individuals from multiple ethnic groups, including admixed ones, will definitely be a challenge but a better understanding of the real utility of genotyping patients on warfarin can be gained.

\section{Financial \& Competing Interests Disclosures}

Dr. Duconge is funded in part by NIH grant \#HL123911 from the National Heart, Lung and Blood Institute (NHLBI); the Research Center in Minority Institutions (RCMI) grants from the National Center for Research Resources (NCRR), award \#2G12-RR003051 and the National Institute on Minority Health and Health Disparities (NIMHD), award \#8G12-MD007600. The author has no relevant affiliations or financial involvement with any organization or entity with a financial interest in or financial conflict with the subject matter or materials discussed in the manuscript. No writing assistance was utilized in the production of this manuscript.

\section{References}

1. Johnson JA, Gong L, Whirl-Carrillo M, Gage BF, Scott SA, et al. (2011) Clinical Pharmacogenetics Implementation Consortium Guidelines for CYP2C9 and VKORC1 Genotypes and Warfarin Dosing. Clin Pharmacol Ther 90: 625-629.

2. Perini JA, Struchiner CJ, Silva-Assuncao E, Santana IS, Rangel F, et al. (2008) Pharmacogenetics of warfarin : development of a dosing algorithm for Brazilian patients. Clin Pharmacol Ther 84:722-728.
3. Wu AHB, Wang P, Haller C, Drake K, Linder M, et al. (2008) Dosing algorithm for warfarin using CYP2C9 and VKORC1 genotyping from a multi-ethnic population: comparison with other equations. Pharmacogenomics 9: 169-178.

4. Daneshjou R, Tatonetti NP, Karczewski KJ, Sagreiya H, Bourgeois S, et al. (2013) Pathway analysis of genomic-wide data improves warfarin dose prediction. BMC Genomics 14: S11.

5. Takahashi $H$, Wilkinson GR, Nutescu EA, et al. ( 2006) Different contributions of polymorphisms in VKORC1 and CYP2C9 to intra- and inter-population differences in maintenance doses of warfarin in Japanese, Caucasians and African Americans. Pharmacogenet Genomics 16: 101-110.

6. Limdi NA, Arnett DK, Goldstein JA, Beasley TM, McGwin G, et al. (2008) Influence of CYP2C9 and VKORC1 on warfarin dose, anticoagulation attainment and maintenance among European-Americans and AfricanAmericans. Pharmacogenomics 9: 511-526.

7. Perera MA, Cavallari LH, Limdi NA, Gamazon ER, Konkashbaev A, et al. (2013) Genetic variants associated with warfarin dose in African-American individuals: a genome-wide association study. Lancet 382: 790-796.

8. Cavallari LH, Langaee TY, Momary KM, Shapiro NL, Nutescu EA, et al. (2010) Genetic and clinical predictors of warfarin dose requirements in African Americans. Clin Pharmacol Ther. 87: 459-64.

9. Kimmel SE, French B, Kasner SE, Johnson JA, Anderson JL, et al. (2013) A Pharmacogenetic versus a Clinical Algorithm for Warfarin Dosing. $\mathrm{N}$ Engl J Med 369: 2283-2293.

10. Pirmohamed M, Burnside G, Eriksson N, Jorgensen AL, Toh CH, et al. (2013) A Randomized Trial of Genotype-Guided Dosing of Warfarin. N Engl J Med 369: 2294-2303.

11. Ruaño G, Duconge J, Windemuth A, Cadilla CL, Kocherla M, et al. (2009) Physiogenomic analysis of the Puerto Rican population. Pharmacogenomics 10: $565-577$.

12. Villagra D, Duconge J, Windemuth A, Cadilla CL, Kocherla M, et al. (2010) CYP2C9 and VKORC1 genotypes in Puerto Ricans: A case for admixturematching in clinical pharmacogenetic studies. Clin Chim Acta 411: 1306-1311.

13. Duconge J, Ruaño G (2010)Emerging Role of Admixture in the Pharmacogenetics of Puerto Rican Hispanics. J Pharmacogenom Pharmacoproteomics 4: 101.

14. Bress A, Patel SR, Perera MA, Campbell RT, Kittles RA, et al. (2012) Effect of NQO1 and CYP4F2 genotypes on warfarin dose requirements in HispanicAmericans and African-Americans. Pharmacogenomics 13: 1925-1935

15. Parra EJ, Kittle RA, Shriver MD (2004) Implications of correlation between skin color and genetic ancestry for biomedical research. Nature Genetics 36: S54-S60.

16. Suarez-Kurtz G, Perini JA, Bastos-Rodriguez L, Peña SD, Struchiner C (2007) Impact of population admixture on distribution of the $C Y P 3 A 5^{\star} 3$ polymorphism. Pharmacogenomics 8: 1299-1306.

17. Estrella RCE, Ribeiro FS, Carvalho RS, Neto ED, Struchiner C, et al. (2008) Distribution of $A B C B 1$ polymorphisms among Brazilians: impacts of population admixture. Pharmacogenomics 9: 267-276. 